\title{
Mitarbeiter dieses Heftes
}

PD Dr. Klaus Arnold, Diplom-Journalist, ist wissenschaftlicher Assistent am Lehrstuhl für Journalistik II an der Katholischen Universität Eichstätt-Ingolstadt.

Prof. Andreas Büsch, Diplom-Theologe und Diplom-Pädagoge, lehrt Medienpädagogik und Kommunikationswissenschaft an der Katholischen Fachhochschule in Mainz.

Dr. Christian Kolmer, M.A., ist Medienwissenschaftler und Historiker und arbeitet seit 1994 als wissenschaftlicher Mitarbeiter für das Forschungsinstitut Media Tenor.

Dr. Ferdinand Oertel hat als Chefredakteur für verschiedene katholische Printmedien gearbeitet und lebt als freier Autor in Aachen.

Bernhard Rude, M.A. ist seit Februar 2000 Studienleiter für die Ausbildung von Volontären an Tageszeitungen beim Institut zur Förderung publizistischen Nachwuchses in München.

Prof. Dr. em. Ulrich Saxer war Ordinarius für Publizistik an der Universität Zürich und Ordinarius für Kommunikationssoziologie an der Università della Svizzera Italiana in Lugano. Er lehrt als Gastprofessor an der Universität Wien.

Manuel Wendelin, M. A., ist wissenschaftlicher Mitarbeiter am Institut für Kommunikationswissenschaft und Medienforschung der Ludwig-Maximilians-Universität München. 